openUP

\title{
The role of asymmetric information on investments in emerging markets
}

\author{
W.A. de Wet
}

\begin{abstract}
This paper argues that, because of asymmetric information and adverse selection, forces other than fundamentals may play an immense role in investment flows to emerging markets. When information is distributed asymmetrically between those who make decisions (the government) and the theoretical beneficiaries (investors), optimal investment behaviour is distorted. Information, which is hidden from investors, affects a country adversely, even though it may not be negative in nature. As a consequence of asymmetric information, other more serious problems, which in the long run can prove to be very costly, could appear. The paper applies a model developed by Greenwald and Stiglitz (Asymmetric Information, Corporate Finance, and Investment (1990)) to test for the presence of credit rationing in these markets.
\end{abstract}

Keywords: Imperfect information; Rationing; Adverse selection; Contagion

\section{Introduction}

In recent years, there has been growing concern with regard to the fragility of financial systems. Policymakers are faced with the questions of what they should do to prevent financial crises. This paper seeks to understand the nature of financial 'contagion' through investor behaviour and herding. It has been observed time and again that shocks to world markets or one emerging market affect all emerging markets alike. Furthermore, this study seeks to examine some of the reasons for and consequences of unexplained underinvestment phenomena in certain emerging markets.

In this paper, it is argued that other forces, because of asymmetric information and adverse selection, may play an immense role in investment flows to emerging markets. When information is distributed asymmetrically between those who make decisions (the government) and the theoretical beneficiaries (investors) optimal investment behaviour is distorted. Information which is hidden from investors affects a country adversely even though it may not be negative in nature. As a consequence of asymmetric information, other more serious problems could appear, that in the long run might prove to be very costly. 


\section{The problem of asymmetric information}

The asymmetric information literature, which looks at the impact of the financial structure on economic activity focuses on the differences in the information available to different parties in financial contracts (Miskin, 1990). Borrowers have an informational advantage over lenders because the former know more about investment projects they wish to undertake than the latter do. This asymmetry of information between principal and agent leads to the classic 'lemons' problem described by Akerlof (1970). A 'lemons' problem occurs in the debt market because lenders have trouble determining whether a borrower is at good risk with good investment opportunities, or at bad risk with high-risk investment opportunities. If lenders cannot distinguish between borrowers of good quality and borrowers of bad quality (i.e. the 'lemons'), they will only make loans available at the interest rate that reflects the average quality of good and bad borrowers. The result is that high quality borrowers will be paying a higher interest rate than they should, because low quality borrowers are paying a lower interest rate than they should. A possible result of this 'lemons' problem is that high quality borrowers might drop out of the market, leaving only low quality borrowers, which in turn leads to a breakdown of the market.

Another result of asymmetric information is that it may lead to credit rationing. Higher interest rates lead to even greater adverse selection, because borrowers with the riskiest projects are now most likely to take out loans at a higher interest rate. If the lender cannot discriminate between good borrowers (low risk) and bad borrowers (high risk), he/she may rather cut down the number of loans made. This causes the supply of loans to decrease with the higher interest rate rather than to increase (Stiglitz and Weiss, 1981). Mankiw (1986) also demonstrated that a small rise in the riskless interest rate could lead to a very large decrease in lending, and even to the possible collapse of the market. In times of market uncertainty, it is difficult for lenders to screen out good borrowers from bad borrowers, and the adverse selection problem may increase dramatically, in turn leading to a sharp decline in investment and aggregate activity.

Furthermore, asymmetric information between borrowers and lenders also results in the problem of moral hazard. Borrowers have the incentive to engage in activities that may be personally beneficial, but the probability of default increases and thus harms the lender. The examples are manifold. Borrowers may have the incentives to disregard agreements and misallocate funds for their own personal use, or undertake investment projects that are unprofitable but increase power and stature.

The asymmetric approach provides a possible transmission mechanism for explaining how an increase in asymmetric information might cause funds to be misallocated to the wrong borrowers. It gives a possible explanation of credit rationing to certain borrowers even though funds are available and borrowers are willing to pay higher interest rates. It also gives a possible explanation of why positive net present value projects are not explored, because of adverse selection and moral hazard. ${ }^{1}$ 


\section{Asymmetric information and emerging markets}

When investors invest in emerging markets, they often regard emerging economies as a group, separate from industrialised countries. ${ }^{2}$ These emerging markets tend to be more risky, but expected return is also higher than in industrial countries. Therefore, it can be argued that emerging markets are a basket of countries with one important characteristic in common; they are all risky, or at least relatively more risky than industrial economies. In times of volatile world markets, the emerging market group of countries is usually more affected by volatility.

Institutional investors often hold government bonds of emerging economies as part of a portfolio. The reasons for holding these instruments range from portfolio guidelines or hedging to pure speculation and arbitrage trading. Each of these investors effectively becomes a lender to the country which issues the bond.

When markets become more volatile, uncertainty increases. Uncertainty in markets clouds the information available to investors, and as a result asymmetry in information increases. It becomes increasingly difficult or expensive for investors to distinguish between good borrowers and bad borrowers (the 'lemons'), and the similar problem may arise as described in Section 2 above.

In times of uncertainty, investors might refrain from investing in emerging markets (i.e. ration their credit or investment) rather than accepting higher interest payments

\footnotetext{
${ }^{1}$ Myers and Majluf (1984) describe how the inability of investors to distinguish between good and bad issuers of equity, can result in high quality firms receiving a lower price for their shares than the fair market value, while low-quality firms may receive a price above their fair market value. As a result some high quality firms will not issue shares and so investment projects with a positive net present value will not be undertaken.

${ }_{2}$ Rigibon (2002) shows that the contemporaneous effects between non-investment grade markets are very high, while the contemporaneous effects between non-investment grade markets and investment grade markets are low, meaning that these markets can be regarded as segmented.
} 
on their holdings for reasons as outlined by Stiglitz and Weiss (1981). This in turn will result in the sale of emerging market bonds, increasing the supply of these bonds, pushing down prices and increasing interest rates along the term structure. As a result, a whole range of other problems arises as this effect filters through to the rest of the economy. The effect on the aggregate economy differs depending on the structure of the economy. If the majority of the bonds are denominated in domestic currency, currency depreciation may result, and may trigger a sell-off in the stock market. Higher interest rates may directly result in a decline of the stock market and depreciation of the exchange rate. The list of factors that influence the economy thereafter is extensive.

Increasingly asymmetric information causes adverse selection, inefficient capital flows and moral hazard problems to appear.

\section{Testing for investment rationing}

Greenwald and Stiglitz (1990) describe a model that is ideally suited to testing for credit rationing, or in this case, investment rationing. In their model, banks supply loans to firms without full information pertaining to their probability of default. Perez (1998) also uses their model to test for credit rationing in the loan market for firms in the United States. The Greenwald-Stiglitz model can be summarized in the following three equations:

$$
\begin{aligned}
& D=\alpha_{1} r+\alpha_{2} X+\mu_{1} \\
& S=\beta_{1} r+\beta_{2} Z+\mu_{2} \\
& c=\delta_{1} Y+\mu_{3}
\end{aligned}
$$

The quantity demanded (Eq. (1)) is a function of interest rates (r), other variables $(X)$ and some random error term $\left(\mu_{1}\right)$. The supply (Eq. (2)) is a function of the interest rate $(r)$, other variables $(Z)$ and some random error term $\left(\mu_{2}\right)$. The ceiling is a function of borrower specific characteristics $(Y)$ and some random error term $\left(\mu_{3}\right)$. In order to link investor sentiment with country performance, government bonds are taken as the measure of country performance or an indicator of being a 'good borrower'. If the demand for the bonds $(B)$ issued by a government, is high, it indicates that investors have high confidence in the economy. If the supply of bonds issued by a government is greater than demand for bonds, it indicates a lack of confidence in the country's outlook. Although the government might want to issue new bonds, it will not be able to find buyers for its bonds since there is a ceiling. Why does the ceiling exist? According to Stiglitz and Weiss (1981) there is a certain level of interest rate at which lenders will not lend money to borrowers, but rather ration credit, because of the adverse selection problem. In a similar way, investors might not lend funds to governments, i.e. buy government bonds, if uncertainty increases because of the adverse selection problem. It is mainly this difference between demand and supply that determines the ceiling of a country, 
beyond which investors will not invest even if the government is willing to pay higher coupons on its issued bonds. The level of the short-term interest rate is used as a proxy for the opportunity cost of investing in a country.

To test for investment rationing, one must test for an excess supply of government bonds. Ideally, a sample of emerging markets could be used to estimate demand, supply and interest rate-ceiling curves. Using these three equations, the presence of excess supply can be measured. However, available bond data do not allow for this type of analysis. The researcher is only able to observe the combination of bonds issued and the corresponding interest rates. For example, if a government issues bonds at equilibrium, the prevailing interest rate will be less than the interest rate ceiling. The ceiling is, therefore, latent. Eqs. (1) and (2) determine the quantity of bonds (B) and r, while Eq. (3) determines the latent variable $c$. In the case of rationed investment, the supply of bonds exceeds the demand for bonds. Therefore, the observed amount of bonds corresponds to the amount demanded. The observed interest rate corresponds to c, and the supply equation (Eq. (2)) is latent.

Not only is the researcher unable to observe a given variable in a given situation, but he/she does not know which countries are rationed. Unknown sample separation, therefore, exists. Under these circumstances, evaluation of the three equations necessitates the development of a likelihood function that accounts for variable latency and the lack of sample separation. Quandt (1988) gives an in-depth discussion of testing in disequilibrium models.

\subsection{Derivation of the likelihood function}

In bond market equilibrium, Eqs. (1) and (2) determine the number of bonds traded, $B$, and the interest rate, r. Eq. (3) goes unobserved, because $c$ is greater than r. Assume that the error terms are distributed normally and the endogenous variables are distributed in a multivariate normal manner. Define $f(B, r, c)$ as the probability density function derived from Eqs. (l)-(3), if the data are generated under equilibrium.

In the rationed regime, the market clearing interest rate exceeds the ceiling $(r>c)$. In this case, only the interest rate ceiling and the number of bonds demanded are observed and determined by Eqs. (1) and (3). Define $z(S, B, r)$ as the probability density function derived from Eqs. (1)-(3) if the data are generated under rationing. The two density functions are different since they are determined by different equations.

For the sample with unknown separation, it is impossible to determine which trades are made under equilibrium conditions and which under rationed conditions. The density of $B$ and $\mathrm{r}$ for each observation combines the densities from the equilibrium and rationed regimes:

$h^{\mathrm{m}}(B, r)=\operatorname{Prob}(r<c) h^{\mathrm{e}}(B, r / r<c)+\operatorname{Prob}(r>c) h^{\mathrm{r}}(B, r / r>c)$ 
The individual density functions are derived from $/(\bullet)$ and $z(')$ by integrating out the latent variable:

$h^{\mathrm{e}}(B, r / r<c)=\int_{r}^{\infty} f(r, B, c / r<c) \mathrm{d} c=\left(\frac{1}{\operatorname{prob}(r<c)}\right) \int_{r}^{\infty} f(r, B, c) \mathrm{d} c$

$h^{\mathrm{r}}(B, r / r>c)=\int_{B}^{\infty} z(r, B, S / r>c) \mathrm{d} S=\left(\frac{1}{\operatorname{prob}(r>c)}\right) \int_{B}^{\infty} z(r, B, S) \mathrm{d} S$

The limits of integration are determined by analysis of the latent variable. In equilibrium, $c$ is not observable. The limits for $c$ thus go from $r$ to infinity. Similarly, the limits of integration for $S$ in the rationed regime go from $B$ to infinity. The density function for $B$ and $r$, in a sample with unknown separation, combines the two integrals:

$h^{\mathrm{m}}(B, r)=\int_{r}^{\infty} f(r, B, c) \mathrm{d} c+\int_{B}^{\infty} z(r, B, S) \mathrm{d} S$

Assuming that the error terms are distributed in an independent, normal manner, allows for further simplification:

$\mu=\left[\mu_{1}, \mu_{2}, \mu_{3}\right]^{\prime} \sim N\left(0, \sum\right), \quad 0=\left[\begin{array}{lll}0, & 0,0\end{array}\right]^{\prime}$, and $\sum=\left[\begin{array}{ccc}\sigma_{1}^{2} & 0 & 0 \\ & & \\ 0 & \sigma_{2}^{2} & 0 \\ & & \\ 0 & 0 & \sigma_{3}^{2}\end{array}\right]$

where $\sigma_{i}$ for $i=1,2,3$ is the variance of the error terms. Now the density can be written as:

$h^{\mathrm{m}}(B, r)=f_{\mathrm{e}}(B, r) \int_{r}^{\infty} f(c) \mathrm{d} c+z(B, r) \int_{B}^{\infty} z(S) \mathrm{d} S$

where $f_{e}(B, r)$ is the probability of $B$ and $\mathrm{r}$ under equilibrium and $\int_{r}^{\infty} f(c) \mathrm{d} c$

represents the probability that $c$ exceeds $r$ observed in the market. The same goes for the rationed regime in the second term on the right hand side of Eq. (9). The probability of the entire sample is the product of each individual density: ${ }^{3}$

$L^{\mathrm{m}}=\prod_{\text {all countries }} h^{\mathrm{m}}(B, r)(10)$

\footnotetext{
${ }^{3}$ Quandt (1988:33); Gourieroux and Monfort (1980).
} 
This probability partitions information from each observation to the parameter in the regime from which the observation was most likely generated. A country that experiences equilibrium has a high probability that $c$ is greater than the $\mathrm{r}$ observed in the market and a low probability that $S$ is greater than the observed demand.

\subsection{Tests for disequilibrium}

A test for disequilibrium involves restricting the likelihood to that associated with all countries exhibiting equilibrium and testing whether those restrictions cause the maximum of the likelihood to differ significantly from the likelihood obtained without restrictions. Quandt (1988, 90-96) describes the estimation of excess supply. If the restriction that the countries are all in equilibrium cannot be rejected, the sample does not contain any rationed countries. An equivalent procedure can be performed to test whether countries all have excess supply.

To perform the tests, likelihood functions for three possible cases, namely all countries are in equilibrium, some countries are in equilibrium and all countries have excess supply, must be estimated. A probability ratio (LR) test can then be applied to determine whether the restrictions are valid or not. The mixed likelihood is described in Eq. (10). The all-equilibrium likelihood, where it is assumed that no countries experience excess supply $(z(r, B)$ is 0$)$, condenses to

$h^{\mathrm{e}}(B, r)=f_{\mathrm{e}}(B, r) \int_{r}^{\infty} f(c) \mathrm{d} c$

$L^{\mathrm{e}}=\prod_{\text {all countries }} h^{\mathrm{e}}(B, r)$

For the case where all countries have excess supply, $f_{e}(B, r)$ equals 0 and the case where all the countries have excess demand condenses to:

$h^{\mathrm{r}}(B, r)=z(B, r) \int_{B}^{\infty} z(S) \mathrm{d} S$

$L^{\mathrm{r}}=\prod_{\text {all countries }} h^{\mathrm{r}}(B, r)$

These probabilities can be maximised and the parameters from all three equations identified under the following conditions (Quandt, 1988, 90-91):

- The unobserved equation includes no intercept; and

- All the dependent variables in the unobserved equation change sign.

The statistic used to test the restriction that all the countries are in equilibrium is:

$\mathrm{LR}=-2 \ln \left(L^{\mathrm{e}} / L^{\mathrm{m}}\right)$ 
which is chi-squared distributed with degrees of freedom equal to the number of parameters. A high value of the test statistic implies the null hypothesis that equilibrium for all countries can be rejected. This constitutes a direct test for the existence of investment rationing. Quandt (1988) finds the LR-test to be efficient at identifying a mixed distribution when the null hypothesis of equilibrium is false.

\subsection{The data}

All data were abstracted from the Global Development Indicators of the World Bank, except for the country risk ratings, which were obtained from Euromoney Various macro variables, which are believed to influence the demand and supply of government bonds, were obtained for each of these emerging markets. Due to the large differences in magnitude between variables, all data are expressed as a percentage of gross national product (GNP), except for the value of outstanding bonds which is an actual US\$ value. Where GNP itself is used, it is expressed as a percentage of the GNP of China. The GNP of China, therefore enters any equation as the value one. This implies that all the variables are expressed in percentage form. All data are expressed in US\$ where applicable. During times of uncertainty in world markets it is likely that asymmetric information will be more prevalent than in normal times. For this reason, a cross-section of the 50 countries listed in the Appendix A was taken for the year 1998.

\subsection{Estimation}

Eqs. (l)-(3) are estimated by maximising the mixed likelihood function. A good choice of starting values is essential for convergence of this non-linear likelihood function. Starting values, where applicable, were generated using Ordinary Least Squares.

To estimate the demand curve for bonds, government bonds outstanding (denominated in US dollars) are regressed on the short-term bond rate, GNP, risk (country rating), and the debt/GNP ratio. The rate is restricted to have a negative sign in order to reflect a demand curve. To estimate the supply of bonds by governments, government bonds outstanding (denominated in US dollars) are regressed on rate and GNP of the respective country. The rate is restricted to have a positive sign to reflect a supply curve. The ceiling, at which rationing starts, is calculated as the difference between bonds supplied and demanded, plus the country risk rating. An increase in the gap between demand and supply implies that the ceiling increases, and that rationing is less likely to take place. As the risk of a country increase according to its ratings, the ceiling will decrease, making investment rationing more likely. 
Table 1

Output for the sample of 50 countries

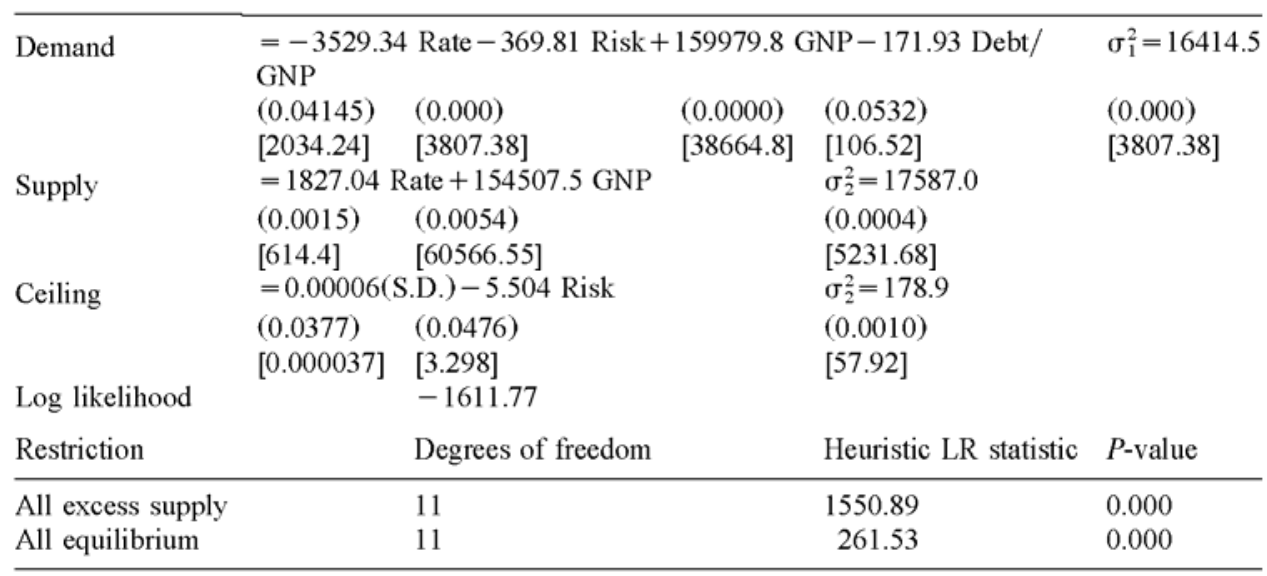

Standard errors are in square brackets and $P$-values are in parentheses.

Table 1 represents output for the estimation of the bond market for the sample of 50 emerging markets. The table includes likelihood ratio statistics for the restriction of allequilibrium and all-rationing and the $P$-vahie with which the null hypothesis in question can be rejected. A small P-vahie implies that data came from the regime implied by the null hypothesis. In the case of the equilibrium restriction, a rejection of the null hypothesis of equilibrium implies that some countries are rationed. The parameters of the supply and demand equations are significant and consistent with a priori expectations. From the LRtest statistics the null of all-equilibrium and the null of all-excess supply are rejected. The mixed equilibrium is accepted in favour of the other two scenarios. Therefore, some countries in the sample are rationed. This rationing indicates that supply is greater than demand.

\section{Conclusion}

This paper argues that it is possible that investment rationing existed in emerging markets in 1998 (in at least the primary bond market). However, this does not exclude other reasons for the under-investment in these markets during this period, but highlights the potential influence of asymmetric information on these markets. Potential investor behaviour described under asymmetric information can impede and slow economic growth in emerging market countries. The year 1998 was investigated since world markets were very volatile during this year. Other more tranquil periods need to be analysed to determine the extent of rationing in other periods. 
openUP

\section{Appendix A: List of countries included in the sample}

\begin{tabular}{ll}
\hline Albania & Latvia \\
Argentina & Lithuania \\
Armenia & Malaysia \\
Bangladesh & Mauritius \\
Barbados & Mexico \\
Botswana & Morocco \\
Brazil & Nigeria \\
Bulgaria & Pakistan \\
Chile & Paraguay \\
China & Peru \\
Colombia & Philippines \\
Comoros & Poland \\
Croatia & Republic of Korea \\
Czech Republic & Russia \\
Dominican Republic & Seychelles \\
Egypt & Slovak Republic \\
Estonia & South Africa \\
Ethiopia & Sri Lanka \\
Honduras & Tanzania \\
Hungary & Thailand \\
India & Turkey \\
Indonesia & Uruguay \\
Jamaica & Venezuela \\
Jordan & Yugoslavia \\
Kenya & Zimbabwe \\
\hline
\end{tabular}

\section{References}

Akerlof, G., 1970. The market for lemons: quality uncertainty and the market mechanism. Quarterly J.

Econ. 89, 488-500. Gourieroux, B., Monfort, A., 1980. Estimation Methods for Markets with Controlled Prices, Discussion paper 8012, INSEE, Paris. Greenwald, B., Stiglitz, J., 1990. Macroeconomic models with equity and credit rationing. In: Glenn

Hubbard, R. (Ed.), Asymmetric Information, Corporate Finance, and Investment, University of Chicago Press, Chicago. Mankiw, N.G., 1986. The allocation of credit and financial collapse. Quarterly J. Econ. August, 101. Miskin, F.S., 1990. Asymmetric Information and Financial Crises: A Historical Perspective, NBER Working Paper, 3400. Myers S., Majluf N., 1984. Corporate Financing and Investment Decisions, when Firms have Information

Investors do not have, J. Financ. Econ. 13 (2) 187-221. Perez, S.J., 1998. Testing for credit rationing: an application of disequilibrium econometrics. J.

Macroecon. 4 (20), 721-739. Quandt, R.E, 1988. The Econometrics of Disequilibrium. Basil Blackwell, New York, NY. Rigibon, R., 2002. The curse of non-investment grade countries. J. Develop. Econ. 69. Stiglitz, J.E., Weiss, A., 1981. Credit rationing in markets with imperfect information. Amer. Econ. Rev.

71, 727-752. 